Article

\title{
Pigment Production by the Edible Filamentous Fungus Neurospora Intermedia
}

\author{
Rebecca Gmoser*(D), Jorge A. Ferreira, Magnus Lundin, Mohammad J. Taherzadeh and \\ Patrik R. Lennartsson \\ Swedish Center for Resource Recovery, University of Borås, 50190 Borås, Sweden; jorge.ferreira@hb.se (J.A.F.); \\ magnus.lundin@hb.se (M.L.); mohammad.taherzadeh@hb.se (M.J.T.); patrik.lennartsson@hb.se (P.R.L.) \\ * Correspondence: rebecca.gmoser@hb.se; Tel.: +46-731-77-84
}

Received: 23 January 2018; Accepted: 9 February 2018; Published: 13 February 2018

\begin{abstract}
The production of pigments by edible filamentous fungi is gaining attention as a result of the increased interest in natural sources with added functionality in the food, feed, cosmetic, pharmaceutical and textile industries. The filamentous fungus Neurospora intermedia, used for production of the Indonesian food "oncom", is one potential source of pigments. The objective of the study was to evaluate the fungus' pigment production. The joint effect from different factors (carbon and nitrogen source, $\mathrm{ZnCl}_{2}, \mathrm{MgCl}_{2}$ and $\mathrm{MnCl}_{2}$ ) on pigment production by $\mathrm{N}$. intermedia is reported for the first time. The scale-up to $4.5 \mathrm{~L}$ bubble column bioreactors was also performed to investigate the effect of $\mathrm{pH}$ and aeration. Pigment production of the fungus was successfully manipulated by varying several factors. The results showed that the formation of pigments was strongly influenced by light, carbon, $\mathrm{pH}$, the co-factor $\mathrm{Zn}^{2+}$ and first- to fourth-order interactions between factors. The highest pigmentation $(1.19 \pm 0.08 \mathrm{mg}$ carotenoids/g dry weight biomass) was achieved in a bubble column reactor. This study provides important insights into pigmentation of this biotechnologically important fungus and lays a foundation for future utilizations of $N$. intermedia for pigment production.
\end{abstract}

Keywords: pigments; neurospora intermedia; carotenoids; edible filamentous fungi; ascomycetes

\section{Introduction}

Pigments used in the food, feed and cosmetic industries are obtained via synthetic or natural routes [1]. The first synthetic pigment "mauve" (aniline purple), by William Henry Perkin in 1856, marked the beginning of the modern color industry. This led to the replacement of natural pigments by synthetic ones mainly due to their lower cost, higher stability, and ease of large-scale production possibilities [2]. However, the consumers' increasing interest in human safety and environmental conservation has led to the request for natural sources of pigments. Natural-origin pigments are used extensively in animal feed to improve the nutritional profile and as a colorant to enhance appearance. For instance, the color of poultry skin, salmon meat and shade of egg yolks is largely determined by the animal's diet. The pigments have potential antioxidant [3] and antitumor properties, which can add functionality to the products [4]. For example, the carotenoid pigment group has antioxidant and provitamin A activity [5].

New potential sources of natural pigments are thus highly desired. Plants have so far been the predominant source of natural pigments, but their use is limited by the irregularity of harvests, land use regulations and their labor-intensive character [6,7].

Pigments from plants as well as fruits also compete for the same cropland and are considered to compete with food production. Pigments can also be produced by some filamentous fungi, which are gaining interest as a promising fermentation-derived natural pigment alternative $[8,9]$. In the food 
and feed industry, there is a special focus on edible filamentous fungi. One such fungi is Neurospora intermedia, which is able to produce yellow-to-orange carotenoids. N. intermedia is used to produce the Indonesian traditional dish "oncom merah", which could make it easier to overcome any regulatory obstacles of using its pigments since it is already used in food [10,11]. Further advantages include no detected production of mycotoxins after more than two centuries of research and an ability to grow rapidly on various types of substrates [12]. The biomass produced by N. intermedia is rich in essential amino acids, omega- 3 and -6 fatty acids and can easily be separated from the fermentation broth [13]; thus, the fungal biomass is a good potential source of high-quality nutrients for animal or fish feed application. Therefore, the extra pigment produced will increase the value of the feed without adding any additional work. In all, $N$. intermedia poses great potential for industrial applications. However, research using $N$. intermedia for pigment production is scarce in the literature [14], with only a few studies on pigment production $[1,8]$. Understanding the factors that regulate pigment biosynthesis in $N$. intermedia is a critical step toward controlling their carotenoid biosynthesis. Several factors, such as oxidative stress, aeration, light, $\mathrm{pH}$, nitrogen and carbon source, are reported to influence pigment production in ascomycetes [15]. In this context, this study presents the influence of carbon and nitrogen sources and trace metals on pigment production by $N$. intermedia. Insights on the influence of the supplied air and $\mathrm{pH}$ were also investigated in a bench-scale bubble column bioreactor.

This work aimed to increase the understanding of the multiple-effect factors influencing the pigment production by $N$. intermedia to further the utilization of the fungus in biotechnological applications.

\section{Materials and Methods}

\subsection{Fungal Strain}

The edible filamentous ascomycete Neurospora intermedia CBS 131.92 (Centraalbureau voor Schimmelcultures, Westerdijk Fungal Biodiversity Institute, Utrecht, The Netherlands), was used in the current study. The fungus was kept on potato dextrose agar (PDA) containing (g/L): D-glucose 20 , agar 15 and potato extract 4 . The prepared PDA plates were inoculated and incubated aerobically for $3-5$ days at $30^{\circ} \mathrm{C}$ followed by storage at $4{ }^{\circ} \mathrm{C}$. Spore solutions for inoculation were prepared by flooding each plate with $20 \mathrm{~mL}$ sterile distilled water and releasing the spores by agitation with a disposable plastic spreader. All liquid cultures were inoculated with $10 \mathrm{~mL} / \mathrm{L}$ of spore solution with a spore concentration of $6.5( \pm 0.4) \times 10^{5}$ spores $/ \mathrm{mL}$.

\subsection{Submerged Cultivation in Shake-Flasks}

The synthetic medium contained per liter: $0.95 \mathrm{~g} \mathrm{MgCl}_{2}(9.98 \mathrm{mM}), 3.5 \mathrm{~g} \mathrm{KH}_{2} \mathrm{PO}_{4}(25.7 \mathrm{mM}), 1.0 \mathrm{~g}$ $\mathrm{CaCl}_{2} \cdot 2 \mathrm{H}_{2} \mathrm{O}(6.8 \mathrm{mM})$, and different carbon $(100 \mathrm{mM})$ and nitrogen sources $(4 \mathrm{mM})$ were used as the basal screening medium for the pigment production. Furthermore, each flask was supplemented with $20 \mathrm{~mL} / \mathrm{L}$ trace metal solution [16]. Two carbon sources were investigated for their effect on pigment production, namely, glucose and mannose. Temperature of $35{ }^{\circ} \mathrm{C}$ was used for all the screening cultures, the nitrogen source was either $\mathrm{NaNO}_{3}$ or $\mathrm{NH}_{4} \mathrm{Cl}$, and the metal ions added beyond the standard trace metal solution were $10 \mathrm{mM}$ of $\mathrm{ZnCl}_{2}, \mathrm{MgCl}_{2}$ and $\mathrm{MnCl}_{2}$.

All fungal cultures were carried out aerobically in cotton plugged $100 \mathrm{~mL}$ Erlenmeyer flasks (flask diameter of $85 \mathrm{~mm}$ ) containing $50 \mathrm{~mL}$ of medium autoclaved at $121^{\circ} \mathrm{C}$ for $20 \mathrm{~min}$. The carbon/nitrogen and salt solutions were autoclaved separately. A water bath (Grant OLS-Aqua pro, Cambridge, UK) was used to maintain the temperature with orbital shaking at $125 \mathrm{rpm}$ (radius of $9 \mathrm{~mm}$ ) for 6 days under blue light with a peak wavelength centered around $450<\lambda<500 \mathrm{~nm}$, emitting 70 lux. The initial $\mathrm{pH}$ of the medium was adjusted to 5.5 with $2 \mathrm{M} \mathrm{NaOH}$. Samples $(1.5 \mathrm{~mL})$ were taken from the fermentation broth at time 0 and at the end of cultivation, and centrifuged at $1207 \times g$ for $10 \mathrm{~min}$. The supernatant was separated and kept at $-20{ }^{\circ} \mathrm{C}$ until analysis in HPLC. 
A full 25 factorial experiment with two replicates was designed. The selection of factors and levels of these factors were based on a preliminary screening experiment performed by a $2^{6-2}$ reduced factorial experiment (data not shown). Five factors were selected for further investigation, namely, carbon and nitrogen sources, $\mathrm{MgCl}_{2}, \mathrm{MnCl}_{2}$ and $\mathrm{ZnCl}_{2}$ (Table 1).

Table 1. Factors and level of factors included in the full factorial experiment.

\begin{tabular}{ccccc}
\hline Carbon Source (100 $\mathbf{~ M M})$ & Nitrogen Source (4 mM) & $\mathbf{Z n C l}_{\mathbf{2}}(\mathbf{m M})$ & $\mathbf{M g C l}_{\mathbf{2}}(\mathbf{m M})$ & $\mathbf{M n C l}_{\mathbf{2}}(\mathbf{m M})$ \\
\hline Glucose & Ammonium chloride & 10 & 10 & 10 \\
Mannose & Sodium nitrate & 0 & 0 & 0 \\
\hline
\end{tabular}

The full factorial design was chosen to investigate combinations of carbon sources, nitrogen sources and trace metals, using all treatment combinations to obtain main effects and all possible interaction effects between factors for pigment production. All the data obtained were analyzed using a General Linear Model ANOVA (analysis of variance). Factors were considered significant at a p-value less than 0.01 and the effects of treatment combinations were analyzed using Tukey multiple comparison test. Statistical analysis of the data was performed using the software package MINITAB $^{\circledR} 17$ (Minitab Inc., State College, PA, USA). The experimental design resulted in sixteen different combinations for each carbon source with one replication of samples (Table 2).

Table 2. Combination of factors and levels of factors used in the full factorial experiment in shake-flasks for each carbon source $(100 \mathrm{mM})$.

\begin{tabular}{cccc}
\hline Nitrogen Source (4 mM) & $\mathbf{Z n}^{2+}(\mathbf{m M})$ & $\mathbf{M n}^{2+}(\mathbf{m M})$ & $\mathbf{M g}^{2+}(\mathbf{m M})$ \\
\hline $\mathrm{NH}_{4}{ }^{+}$ & 10 & 0 & 10 \\
$\mathrm{NO}_{3}{ }^{+}$ & 10 & 0 & 10 \\
$\mathrm{NH}_{4}{ }^{+}$ & 10 & 10 & 10 \\
$\mathrm{NH}_{4}{ }^{+}$ & 0 & 0 & 10 \\
$\mathrm{NH}_{4}{ }^{-}$ & 10 & 10 & 0 \\
$\mathrm{NO}_{3}{ }^{-}$ & 10 & 10 & 0 \\
$\mathrm{NO}_{3}{ }^{+}$ & 0 & 10 & 10 \\
$\mathrm{NH}_{4} \mathrm{NO}_{3}{ }^{-}$ & 0 & 10 & 10 \\
$\mathrm{NO}_{3}{ }^{-}$ & 10 & 10 & 10 \\
$\mathrm{NH}_{4}{ }^{-}$ & 0 & 10 & 0 \\
$\mathrm{NO}_{3}{ }^{-}$ & 0 & 0 & 0 \\
$\mathrm{NO}_{3}{ }^{-}$ & 0 & 0 & 0 \\
$\mathrm{NO}_{3}{ }^{+}$ & 10 & 0 & 0 \\
$\mathrm{NH}_{4}{ }^{+}$ & 0 & 0 & 10 \\
& 0 & 10 & 0 \\
& 10 & 0 & 0 \\
\hline
\end{tabular}

\subsection{Bubble Column Bioreactor}

Fungal cultivations were carried out in $4.5 \mathrm{~L}$ bench scale airlift bioreactors operated as bubble column bioreactors (Belach Bioteknik, Stockholm, Sweden) with a working volume of $3.5 \mathrm{~L}$. The bioreactor was made of transparent borosilicate glass. Aeration at the rate $0.5 \mathrm{vvm}$ (volumeair/volumemedia/min) was maintained throughout the cultivation, unless otherwise specified, using a sintered stainless-steel air sparger with a pore size of $0.2 \mu \mathrm{m}$. Inlet air was filtered by passing it through a $0.1 \mu \mathrm{m}$ pore size PTFE membrane filter (Whatman, Florham Park, NJ, USA). The same synthetic medium composition and conditions as in the shake-flasks were used, with all ions added to every combination. 
To examine the effect of $\mathrm{pH}$ on pigment production, the medium was adjusted during the cultivation to $\mathrm{pH} 3.5 \pm 0.05$ and $5.5 \pm 0.05$ with $2 \mathrm{M} \mathrm{HCl}, 2 \mathrm{M} \mathrm{NaOH}$ or $10 \mathrm{M} \mathrm{NaOH}$. The combinations were either glucose $(100 \mathrm{mM})$ and sodium nitrate $(4 \mathrm{mM})$ at $\mathrm{pH} 3.5$ and 5.5 , or mannose $(100 \mathrm{mM})$ and ammonium chloride $(4 \mathrm{mM})$ at $\mathrm{pH} 3.5$ and 5.5. The combination of carbon and nitrogen sources chosen was based on results from the full factorial experiment that gave the highest pigmentation response.

The influence of different aeration rates was also tested, namely, $0.17,0.5$ or $1.3 \mathrm{vvm}$, while other parameters remained constant. The cultivation medium was based on glucose (100 mM), sodium nitrate $(4 \mathrm{mM})$ and the trace metals $\mathrm{Zn}^{2+}, \mathrm{Mn}^{2+}$ and $\mathrm{Mg}^{2+}(10 \mathrm{mM})$. The $\mathrm{pH}$ was maintained at $5.5 \pm 0.05$ by addition of $2 \mathrm{M} \mathrm{HCl}$ and $2 \mathrm{M} \mathrm{NaOH}$.

\subsection{Extraction and Estimation of Neurospora Intermedia Orange Pigment}

At the end of the fermentation, the wet biomass from each shake flask, or from the bioreactor, was harvested by pouring the cultivation medium through a $1 \mathrm{~mm}^{2}$ pore area fine mesh and washed with distilled water. Extraction of pigments was carried out according to Singgih, Andriatna, Damayanti and Priatni [8] with some modifications. The washed biomass (50 mg) was then extracted with $3 \mathrm{~mL}$ of 99\% ethanol through sonication for $10 \mathrm{~min}$, followed by centrifugation at $1200 \times g$ for $5 \mathrm{~min}$. The supernatant was separated and the biomass was re-extracted with $99 \%$ ethyl acetate, centrifuged once more and then the supernatant was added to the first extraction solution. The extracted pigments in the ethanol/ethyl acetate solution were analysed spectrophotometrically (Biochrom Ltd., Cambridge, England) at the maximum absorption of $466 \mathrm{~nm}$ and the concentration was determined using a calibration curve for $\beta$-carotene dissolved in the same solution. After extraction, the biomass was dried at $70^{\circ} \mathrm{C}$ for $24 \mathrm{~h}$.

\subsection{Analytical Methods}

A Bürker's counting chamber (with a depth of $0.1 \mathrm{~mm}$ ) was used to determine the spore concentration used for inoculation. The spore solution was diluted ten times after which the spores were counted in $144 \mathrm{E}$-squares $(1 / 125 \mu \mathrm{L})$ under a light microscope (Carl Zeiss Axiostar plus, Oberkochen, Germany), followed by calculation of the final concentration of spores in the solution. High-performance liquid chromatography (HPLC) (Waters 2695, Waters Corporation, Milford, DE, USA) was used to identify and quantify different components in the liquid fractions. An analytic ion-exchange column based on hydrogen ions (Aminex HPX-87H, Bio-Rad Hercules, Berkeley, CA, USA) operated at $60^{\circ} \mathrm{C}$ with a Micro-Guard cation-H guard column (Bio-Rad) and $0.6 \mathrm{~mL} / \mathrm{min} 5 \mathrm{mM}$ $\mathrm{H}_{2} \mathrm{SO}_{4}$ as eluent, was used for the analyses of mannose, glucose and ethanol. A UV absorbance detector (Waters 2487), operating at $210 \mathrm{~nm}$ wavelength, was used in series with a refractive index (RI) detector (Waters 2414).

Thin-Layer Chromatography

Crude carotenoid pigment from $N$. intermedia was loaded onto a silica gel plate (silica gel size: 0.063-0.2 mm. Merck, Damstardt, Germany). The mobile phase was 95:5 n-heptane:ethyl acetate. After running the mobile phase up, the plate was dried with hot air and irradiated with UV-light at $365 \mathrm{~nm}$. After separation of the different compounds based on its polarity, individual compounds appeared as vertically separated spots. Each spot had a retention factor (Rf) which is equal to the distance migrated over the total distance covered by the solvent. The results were compared with $\beta$-carotene standard.

\section{Results}

Novel, safe sources of natural pigments with added functionality are highly sought after in a variety of industries, such as feed and food. In this work, the effect of different factors' ability to promote pigment production by the filamentous fungi $N$. intermedia was studied. Factors were carefully chosen based on preliminary studies and findings. Five factors, namely, carbon source (glucose and mannose), nitrogen source $\left(\mathrm{NaNO}_{3}\right.$ or $\left.\mathrm{NH}_{4} \mathrm{Cl}\right)$ and trace metals $\left(\mathrm{Mg}^{2+}, \mathrm{Mn}^{2+}\right.$ and $\mathrm{Zn}^{2+}$ ) were shown 
to be particularly important regarding pigment production (Table 1). A full factorial experiment was conducted to investigate their effect on pigment production. The main independent variables that showed a significant effect were carbon source and $\mathrm{Zn}^{2+}$ (negative effect). In addition to main effects, up to four-way interactions between factors were shown to influence pigment production. The results are summarized in Table 3 and Figure 1. Scaling up to a bench-scale bubble column bioreactor revealed that low pH (Figure 2) and increased aeration (Figures 3 and 4) significantly favored pigment production.

Table 3. ANOVA-analysis of variances with General Linear Model, summarizing the factors with a significant effect and interaction effect between factors on pigmentation, as well as the model summary. Factors were considered significant at $p<0.01, \times$ refer to multiplication of two factors.

\begin{tabular}{ccc}
\hline Term & T-Value & $p$-Value \\
\hline Constant & 34.61 & 0.000 \\
Carbon & 8.47 & 0.000 \\
Nitrogen & 2.99 & 0.005 \\
Zn & -6.39 & 0.000 \\
Carbon $\times \mathrm{Mg}$ & 4.47 & 0.000 \\
Nitrogen $\times \mathrm{Zn}$ & 12.75 & 0.000 \\
Nitrogen $\times \mathrm{Mg}$ & 7.27 & 0.000 \\
$\mathrm{Zn} \times \mathrm{Mg}$ & 4.22 & 0.000 \\
Mn $\times \mathrm{Mg}$ & 3.13 & 0.004 \\
Carbon $\times$ Nitrogen $\times \mathrm{Zn}$ & 6.27 & 0.000 \\
Carbon $\times$ Nitrogen $\times \mathrm{Zn} \times \mathrm{Mn}$ & 3.01 & 0.005 \\
Carbon $\times$ Nitrogen $\times \mathrm{Zn} \times \mathrm{Mg}$ & 4.37 & 0.000 \\
S & $\mathrm{R}-\mathrm{sq}$ & $\mathrm{R}$-sq(adj) \\
0.0322918 & $93.86 \%$ & $87.92 \%$ \\
\hline
\end{tabular}

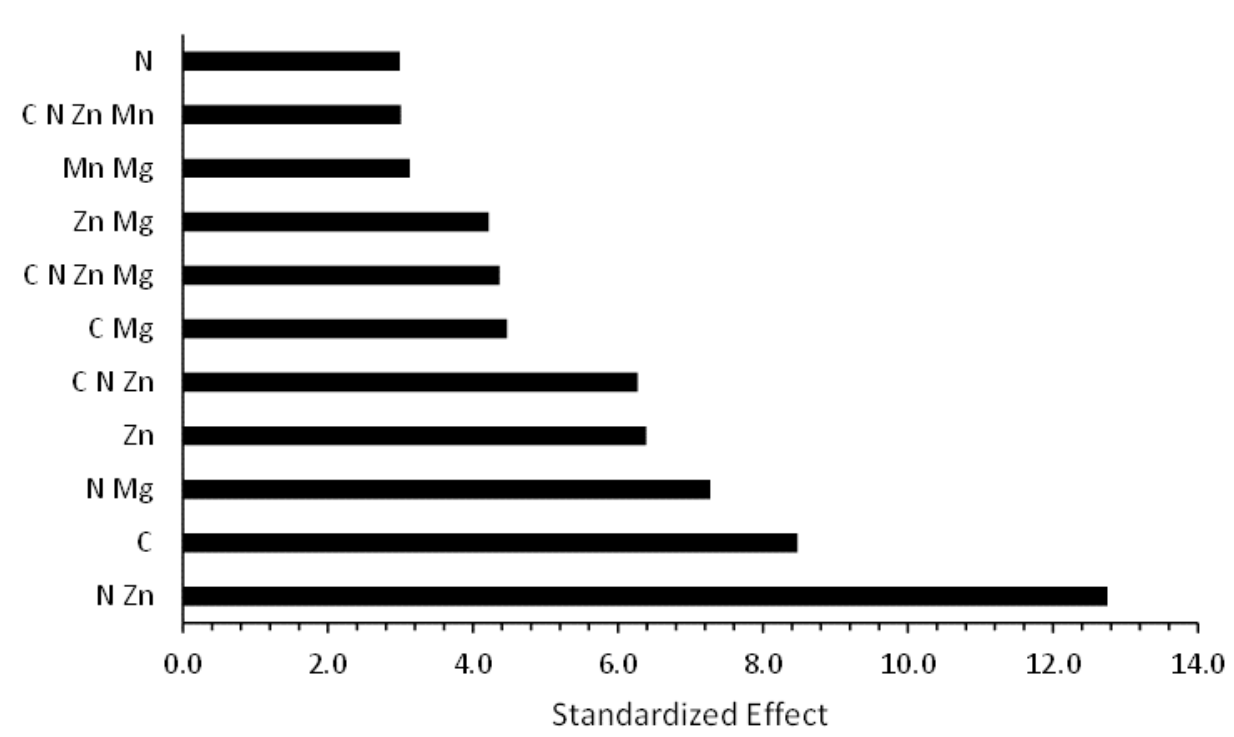

Figure 1. Based on a Pareto chart of the significant $(p<0.01)$ effects for ANOVA analysis of variances using General Linear Model for submerged fermentation by $N$. intermedia. The horizontal axis represents the standardized effect, where the higher effect favors pigment production. The bars are ordered from smallest to largest to get a clear picture of the factors and interaction between factors comprises significant effect on pigment production. $\mathrm{C}=$ carbon, $\mathrm{N}=$ nitrogen, $\mathrm{Zn}=\mathrm{Zn}^{2+}, \mathrm{Mn}=\mathrm{Mn}^{2+}$ and $\mathrm{Mg}=\mathrm{Mg}^{2+}$. 


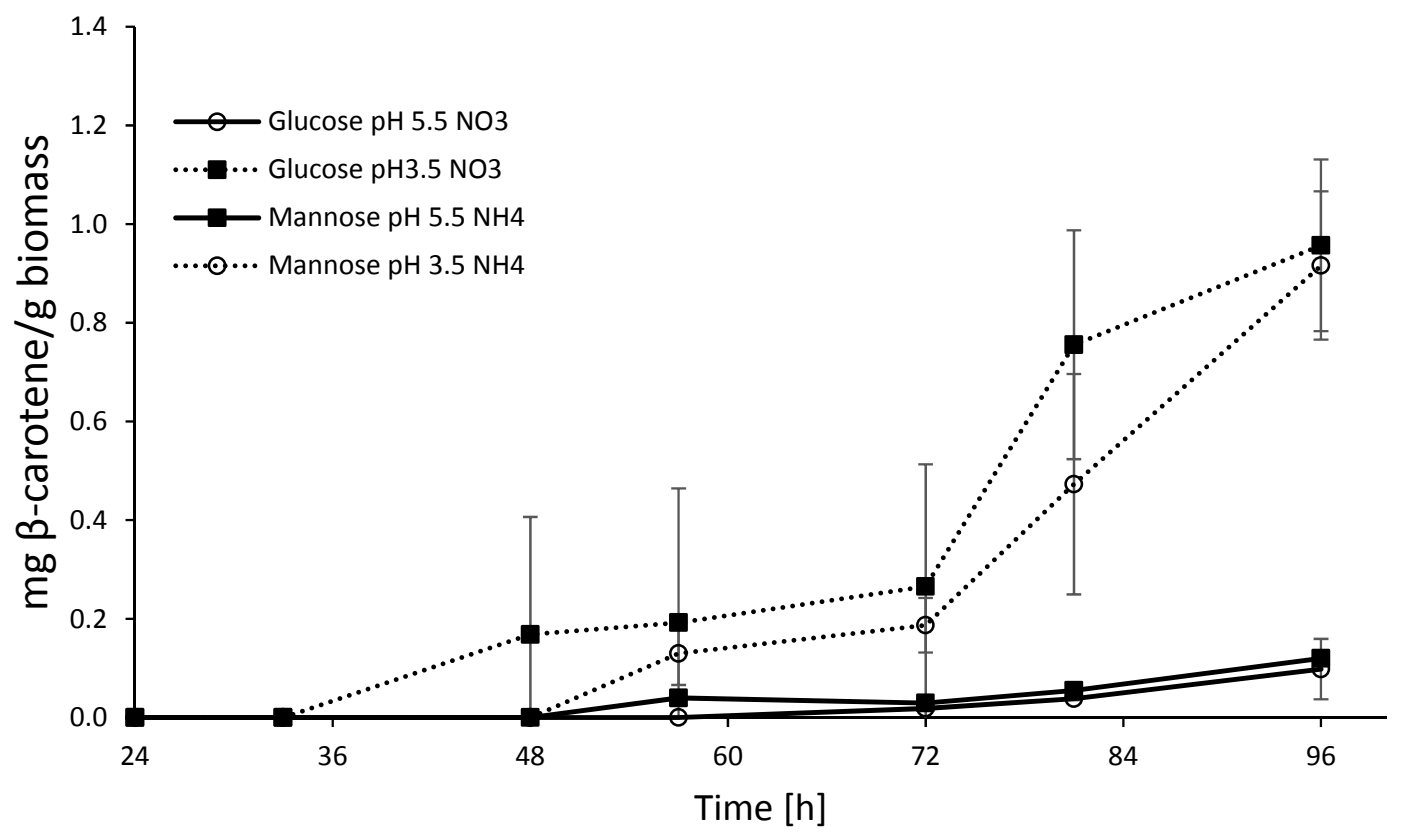

Figure 2. Effect of pH 3.5 (round dotted line) and 5.5 (solid line) using either mannose and ammonium chloride (marked with squares) or glucose and sodium nitrate (marked with circles) on pigment production over time in a bubble column bioreactor. The results were expressed as the mean \pm standard deviation.

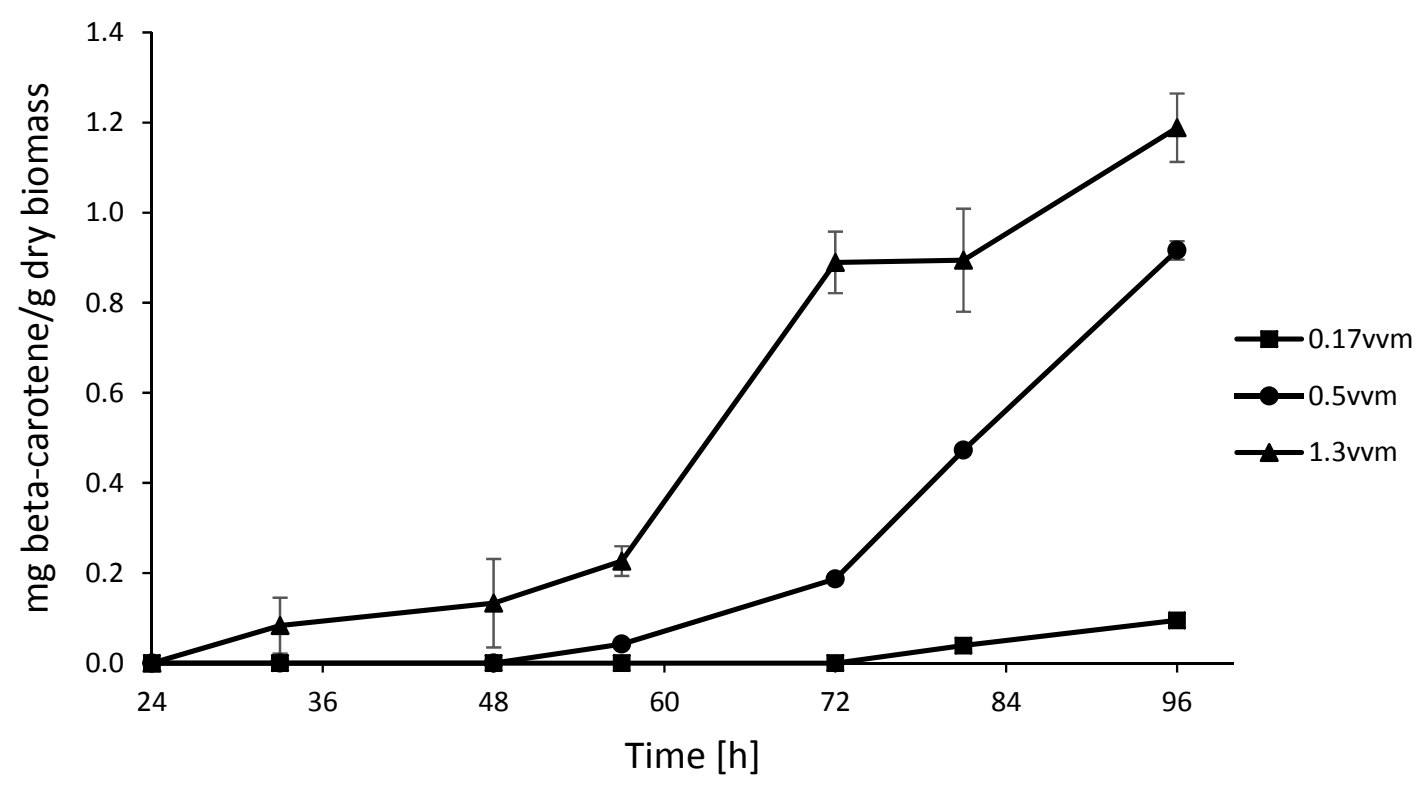

Figure 3. Investigating the effect of the different aeration rates 0.17 (square), 0.5 (circle) and 1.3 (triangle) vvm on pigmentation over time in bubble column bioreactors. Error bars represent the SD of the mean. 

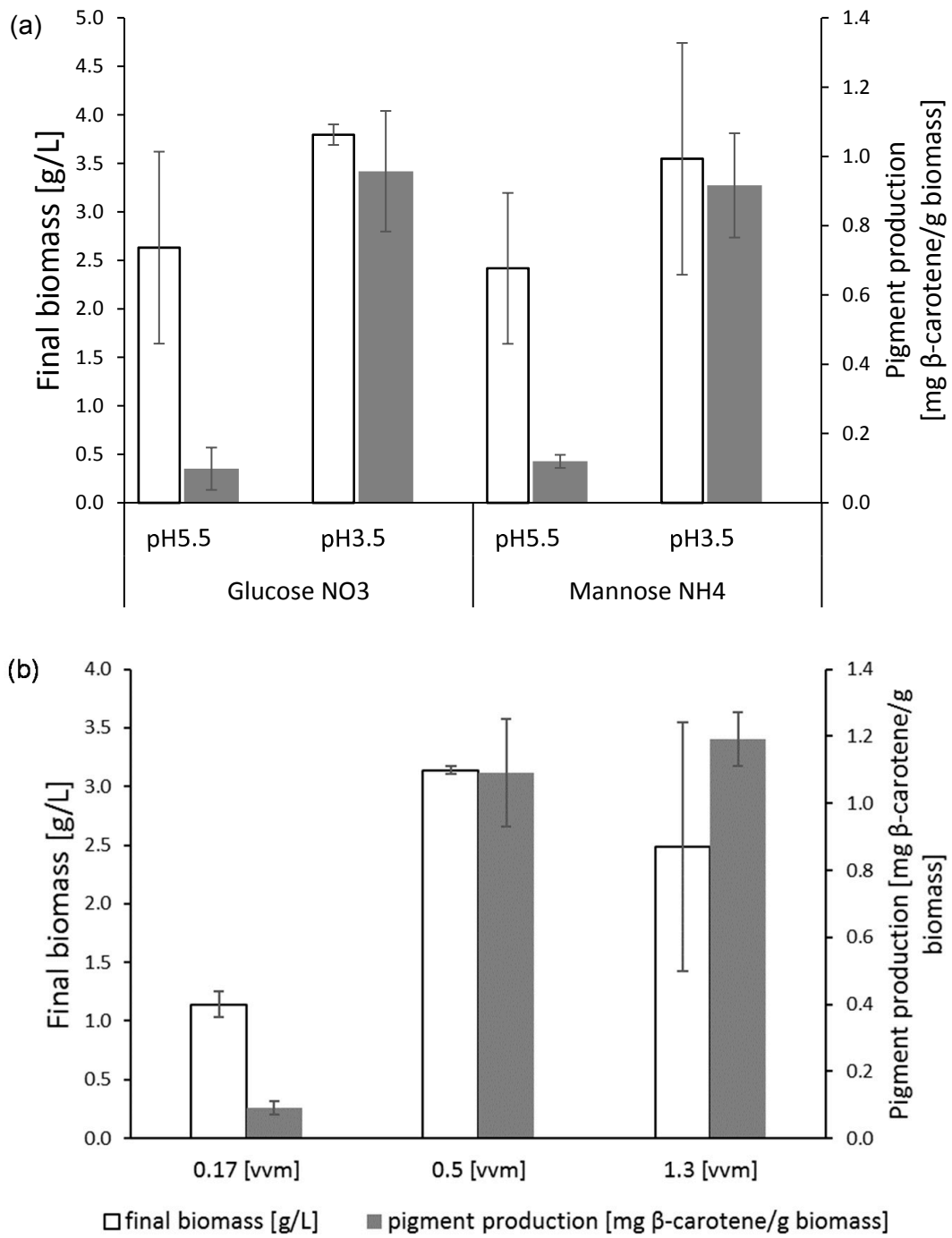

Figure 4. Effect of different $\mathrm{pH}$ values of 3.5 and 5.5 (a); and three different aeration rates (b) on the final biomass (open bars) and pigment production (grey bars) in bubble column bioreactors.

A positive correlation between growth as loose aggregated forms (fluffy pellets) of $N$. intermedia and carotenoid formation appeared, supported by previous studies [17-19]. Since it is not proven whether morphology affects pigment production or whether morphology changes result from some other factor that also affect pigmentation, more thorough studies on the relationship between the cultivation factors, biosynthesis of pigments and mycelial morphology are needed.

\subsection{Effect from Factors on Pigmentation from Full Factorial Design}

To increase the production of pigments by the fungus, a variety of factors possibly influencing pigment production were combined in a submerged fermentation of $N$. intermedia. Factors were selected based on the available literature for pigment production by filamentous fungi and on preliminary screening observations. The preliminary screening revealed that blue light had a significant effect under the response pigment production, as further explained by Sandmann [20]. Only intracellular pigments were produced, as shown by the colorless liquid after removal of the biomass. From the different factors studied, mannose and sodium nitrate were relatively more encouraging for pigment production compared to glucose and ammonium chloride based on the full factorial analysis. The addition of $\mathrm{Zn}^{2+}$ to the media had a mainly negative effect; however, pigment production was favored when $\mathrm{Zn}^{2+}$ was combined with glucose. Mannose promoted pigment production in combination with $\mathrm{Mg}$ ions. 
A second-order interaction between the nitrogen source and $\mathrm{Mg}$ as well as $\mathrm{Zn}$ ions was also found. Sodium nitrate interacted positively with the ions, while ammonium chloride interacted negatively on the pigment production. Furthermore, the addition of $\mathrm{Mg}^{2+}$ and $\mathrm{Zn}^{2+}$ together, or not adding any of them, had a significant positive effect on $N$. intermedia pigment production. The results also revealed a fourth-order interaction between the carbon and nitrogen source, $\mathrm{Zn}^{2+}$ and $\mathrm{Mg}^{2+}$ (Figure 1). For N. intermedia, a complex interaction between factors that promotes higher yields of pigments appears to take place (Table 3). The outcome of the ANOVA can be visualized in Figure 1 based on a Pareto chart. Nitrogen and zinc in combination had the highest effect on pigment production, followed by the carbon source and the combined effect from nitrogen and $\mathrm{Mg}^{2+}$.

\subsection{Effect of Carbon Source}

From the experiments in the bioreactor, carotenoid production was observed from the beginning of hour 33 up to hour 96, with a 15-hour earlier initiation of carotenoid production seen for mannose. One hypothesis from these results would be that changing the carbon source from glucose to mannose may repress the central carbon metabolism and increase the acetyl-CoA pool (the most important precursor for pigment biosynthesis [21]) to pigment biosynthesis rather than cell growth-related pathways. Genes involved in the potential pathways for acetyl-CoA biosynthesis towards pigment production are possibly up-regulated in mannose medium.

In general, the presence of glucose leads to the repression of genes encoding for the metabolism of alternative carbon sources [22,23], but potentially also carotenogenetic enzymes. This phenomenon, termed catabolic repression, has been widely studied for its regulation of carotenogenesis in the yeast Xanthophyllomyces dendrorhous [24]. This highly conserved regulatory mechanism is suggested to be related to the increase in carotenoid production in the presence of mannose rather than glucose. One of these glucose-repressed genes encodes proteins involved in the responses to various stresses [25]. Catabolic repression may at least partly explain the somewhat longer cultivation time needed in order to reach the plateau for carotenoid production when cultivating with glucose compared to mannose. It has been observed that the initiation of carotenogenesis in X. dendrorhous depends on the carbon source present in the culture medium [26], thus supporting the hypothesis. Nevertheless, it seems that the effect of different carbon sources on pigment production varies among fungi species, as media containing glucose have also been widely reported to induce the production of pigments for some fungi [9]. Moreover, a higher order of interaction between the chosen carbon source and other factors possibly influence the production of pigments. The complex interplay between factors, as seen in the full factorial experiment, may result in a positive effect on pigmentation when glucose is used as the carbon source with one combination of factors, while using mannose gives a positive effect with another combination. Choosing one carbon source over the other to promote pigment production is, therefore, not simple.

\subsection{Effect of Addition of Trace Metals}

In N. intermedia, carotenoid production was predicted to be influenced by the co-factors $\mathrm{Mg}^{2+}$, $\mathrm{Mn}^{2+}$ and $\mathrm{Zn}^{2+}$ ions. $\mathrm{Mg}^{2+}$ was shown to promote pigmentation in combination with mannose and hinder pigmentation in combination with glucose. The combined effect of $\mathrm{Mg}^{2+}$ and $\mathrm{Mn}^{2+}$ significantly favored pigment production in N. intermedia. $\mathrm{Zn}^{2+}$ exhibited a negative effect on pigment production when alone, but the negative effect changed to positive when $\mathrm{Zn}^{2+}$ was combined with sodium nitrate or was in the presence of $\mathrm{Mg}^{2+}$.

Related to the effect observed from $\mathrm{Mg}^{2+}$, a study by Singgih, Andriatna, Damayanti and Priatni [8] found that the addition of up to $16 \mathrm{mM}$ of $\mathrm{Mg}^{2+}$ resulted in an increase of carotenoids of $N$. intermedia. $\mathrm{Mg}^{2+}$ was suggested to act as a co-factor for the enzyme phytoene-synthase (al-2) converting geranyl-geranyl pyrophosphate to the colorless carotenoid phytoene (Figure 5), which is an intermediate in the carotenoid biosynthesis. Trace levels of $\mathrm{Mg}^{2+}$ ions, among others, were also reported to increase the rate of carotenogenesis during the growth of mated Blakeslea trispora [27]. The combined 
effect of $\mathrm{Mg}^{2+}$ and $\mathrm{Mn}^{2+}$ ions was largely to be expected, since both ions function as cofactors of carotenogenetic enzymes (Figure 2). For example, the formation of phytoene from precursors requires some cofactors, and $\mathrm{Mn}^{2+}$ together with $\mathrm{Mg}^{2+}$, and ATP are required for the incorporation of the phytoene precursor (MVA) [28]. Since $\mathrm{Mn}^{2}+$ only increased pigment production in combination with $\mathrm{Mg}^{2+}$, manganese-dependent enzymes that regulate the flux in carotenoid production possibly also require $\mathrm{Mg}^{2+}$. Furthermore, the effect of manganese on carotenoid production has been reported to be concentration-dependent, acting as a scavenger [29].<smiles>CCOC(C)=O</smiles>

Acetyl-CoA

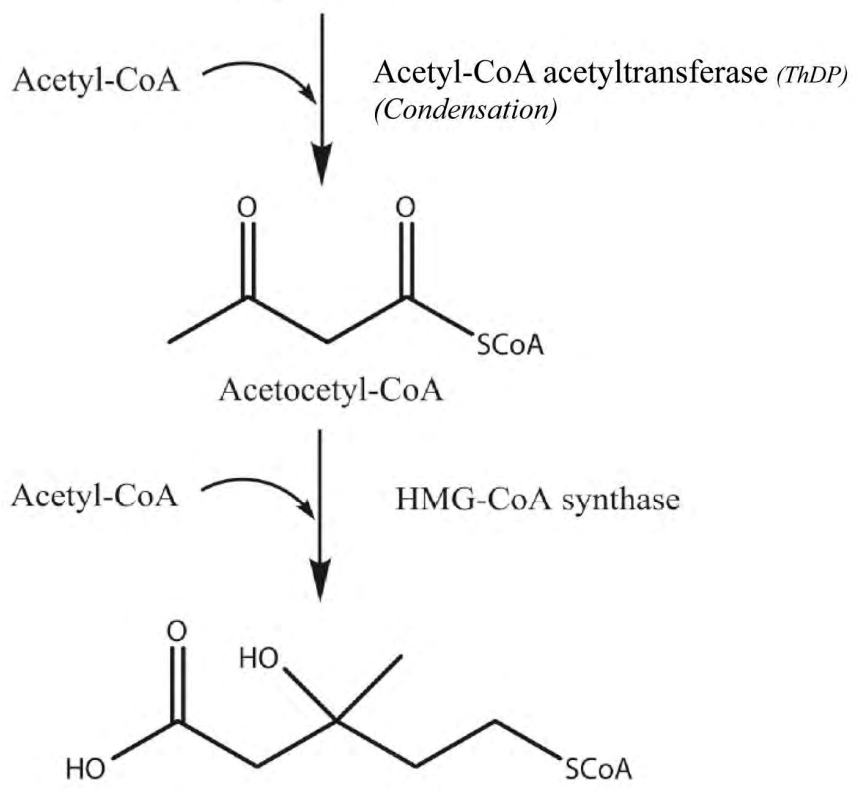

HMG-CoA (3-hydroxy methyl-3-glutaryl-CoA)

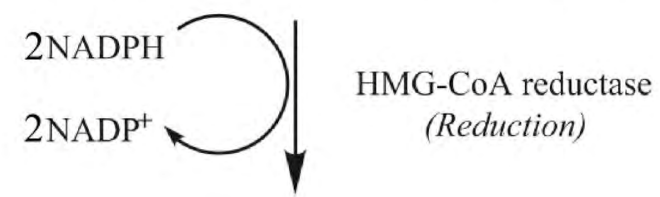<smiles>CC(O)(CCO)CC(=O)O</smiles>

Mevalonate

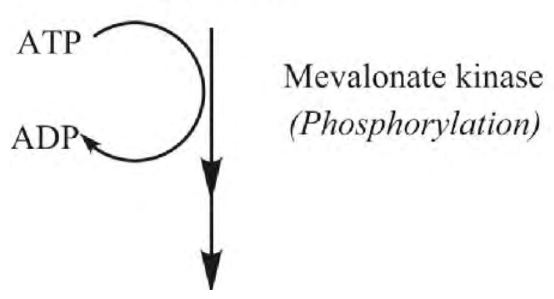

Figure 5. Cont. 


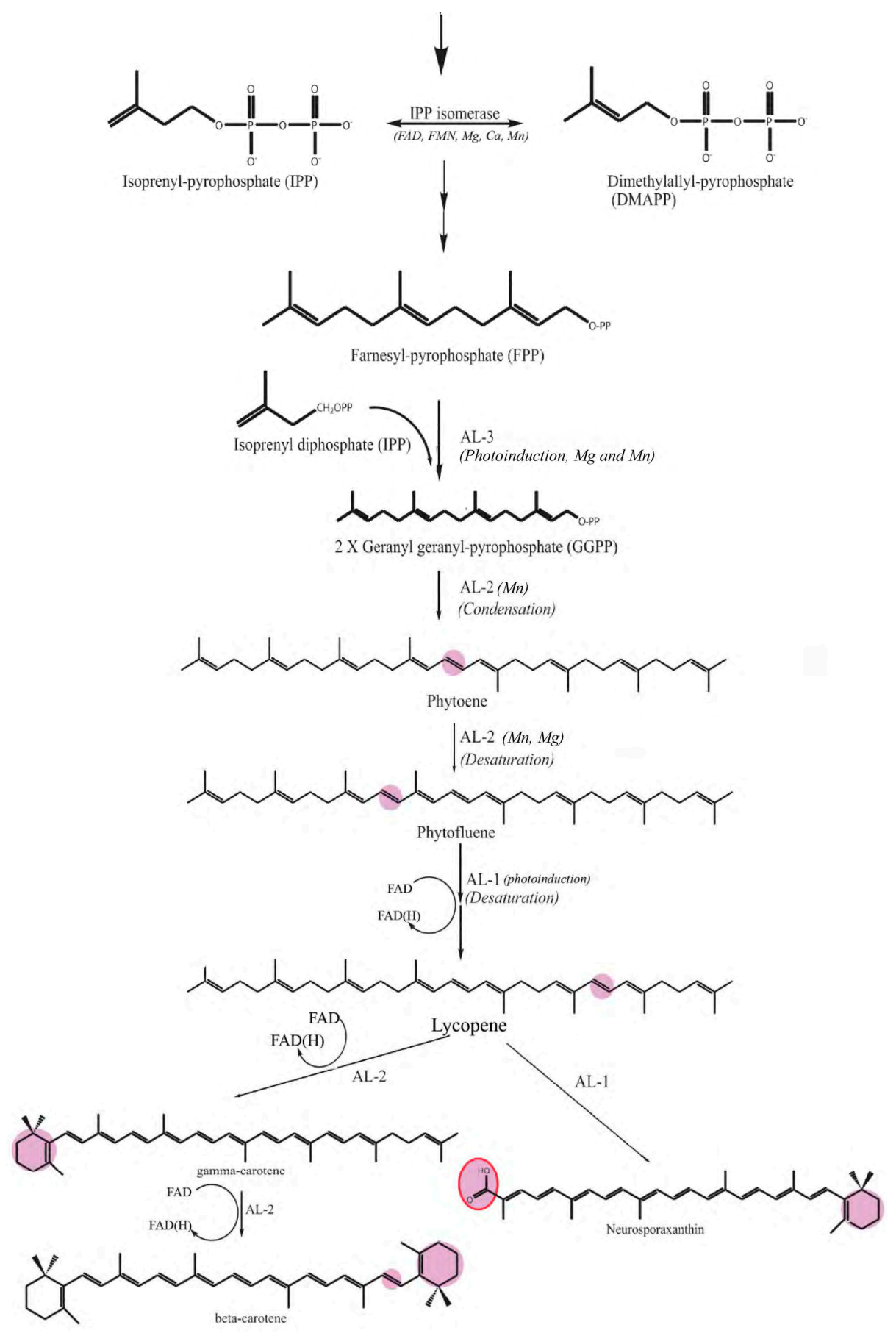

Figure 5. Overview of the carotenoid biosynthesis covering the most important steps regarding regulation, with co-factors needed mentioned in italics [15,30-32] (the purple areas show the functional group -the active sites- in the molecules).

Even though $\mathrm{Zn}^{2+}$ had a negative effect on pigment production, its combinatory effect with other factors had a significantly more positive effect compared with the negative effect of $\mathrm{Zn}$ ions alone. This is probably related to microorganism metabolism. The combinatory effect of zinc and the carbon source has previously been demonstrated in M. purpureus, in which zinc was involved in regulatory processes integrating carbohydrate metabolism [33]. These data also indicate that zinc affects carbohydrate utilization by N. intermedia. However, $\mathrm{Zn}$ ions have not been reported to play as important a role as cofactors for carotenogenic enzymes. 


\subsection{Effect of Nitrogen Source vs. $p H$}

\subsubsection{Nitrogen Source}

The effects of using nitrate or ammonium as the sole nitrogen source were compared in the full factorial experiment. Nitrate had a positive effect on pigment accumulation $(p=0.005)$. This effect was enhanced in the presence of $\mathrm{Zn}^{2+}(p<0.001)$. However, from the scale-up experiments, there was no obvious pattern in pigment production by varying nitrogen sources.

The addition of nitrate [34] or ammonium [35] has previously been reported to promote pigment production in Monascus species. The $\mathrm{pH}$ was not controlled in these studies, suggesting that the nitrogen source may have an indirect effect on pigment production by changing the $\mathrm{pH}$ of the medium. Nevertheless, the nitrogen source may still have an effect in other cultivation conditions such as very limited aeration or nitrogen concentrations. Previous screening trials with $N$. intermedia revealed that a high $\mathrm{C} / \mathrm{N}$ ratio clearly promoted pigment formation, which coincide with previous studies [36,37].

\subsubsection{Effect of $\mathrm{pH}$}

During the shake-flask cultivations, the final $\mathrm{pH}$ values of the different media differed when the source of nitrogen was ammonium chloride, during which the $\mathrm{pH}$ fell to a lower final level compared to media supplemented with nitrate. Since ammonia causes acidification of the medium [38], it was proposed that the change of the $\mathrm{pH}$ had a higher effect than the presence of different nitrogen itself. Therefore, a scale-up of the fungal fermentation in a bubble column bioreactor was performed to enable the constant control the $\mathrm{pH}$ as well as to investigate the scaling-up potential of the pigment production process. The $\mathrm{pH}$ values tested for each combination were 3.5 and 5.5 for mannose together with ammonium chloride and glucose together with sodium nitrate. The results, in Figure 2 , show that the $\mathrm{pH}$ has a substantial effect on pigmentation. A clearly positive relationship between a $\mathrm{pH}$ of 3.5 and pigment production was observed (Figure 2), irrespective of the nitrogen source chosen.

Low $\mathrm{pH}$ levels have previously been reported to positively influence pigmentation in other fungi $[19,39,40]$. The above results indicate that a relatively low $\mathrm{pH}$ seems to be a crucial factor for carotenoid production by N. intermedia. It is conceivable that improving carotenoid production by decreasing the $\mathrm{pH}$ induces mechanisms probably related to a defense response such as oxidative stress in the fungal cells [41].

The effect of $\mathrm{pH}$ has been associated with changes in the activities of proteins [19]. The $\mathrm{pH}$ of the medium possibly had a secondary effect on the regulation of enzymatic processes inside the fungal cell, favoring enzymes involved in carotenogenesis.

The level of hydrogen ions affect the oxidation/reduction process of the molecules in the cell that in turn regulates the oxidative state and redox fluxes of important energy molecules. The different environment in the cell leads to changed metabolic flows and diverse mechanisms of osmotic, oxidative and metabolic regulation and resulting in diverse products such as pigments [19]. Since pigments can help to regulate damage at the membrane level, the production can therefore be affected by this change. These activities have been reported for the Monascus species, where hydrolytic enzymes that induce morphological changes in the cell wall resulted in an overproduction of pigments [42].

\subsection{Aeration}

The effect of the aeration rate on the production of pigments by $N$. intermedia was also studied in bubble column bioreactors. Three different aeration rates were used for the experiment as the sole variable. The supplied air played a crucial role in pigment production (Figure 3). Higher aeration resulted in more pigment accumulation in the biomass $(1.19 \pm 0.08 \mathrm{mg} \beta$-carotene and $1.09 \pm 0.16 \mathrm{mg}$ $\beta$-carotene/g dry biomass at 1.3 and $0.5 \mathrm{vvm}$, respectively, compared to $0.17 \mathrm{vvm}(0.09 \pm 0.02 \mathrm{mg}$ $\beta$-carotene/g dry biomass)). However, the clearest difference between the aeration rates is that an increased aeration led to an earlier initiation of pigment accumulation in the biomass. At the highest aeration rate, $N$. intermedia also consumed the carbon source faster. Pigment production was initiated 
when the carbon source concentration had decreased to approximately 9-11 $\mathrm{g} / \mathrm{L}$ for all experiments in the bioreactors.

Similar results have previously been reported for other fungi. For example, increased pigment production by M. ruber was obtained by cultivating at higher agitation speeds [43]. Similarly, maximum carotene production was obtained by B. trispora at higher dissolved oxygen concentrations (from $50 \%$ to $90 \%$ ) [18]. The production of carotenoids is assumed to be stimulated when oxidative stress occurs to lower the concentration of reactive oxygen species (ROS). In this study, the largest effect was seen in the increase from 0.17 to $0.5 \mathrm{vvm}$, while the change from 0.5 to $1.3 \mathrm{vvm}$ had only a minor impact on pigment production. A potential explanation is that the increase in aeration from 0.17 to 0.5 resulted in enough oxygen for the fungi to start producing pigments. Further increasing the aeration rate to $1.3 \mathrm{vvm}$ only sped up the reactions to some extent since the fungi already had enough oxygen for an initial stress response and pigment biosynthesis.

\subsection{Biomass Production Related to Carotenoid Production}

Fungi grown under stress are commonly less efficient in the conversion of substrates into microbial biomass, causing a failure of the culture to reach the maximal production of biomass and ultimately a lack of an association between microbial growth and pigment production. A negative relationship between growth and pigment production was thus expected, as acetyl-CoA was hypothesized to be effectively converted to biomass instead of pigment formation under favorable conditions (Figure 4), consistent with previous studies $[18,19,44]$. However, a high pigment production was shown to not necessarily result in low amount of biomass when cultivated in shake flasks, as seen in the scatterplot (Figure 6). The scatterplot shows a clear relationship between pigment and biomass produced as the values are randomly spread in the figure. Nevertheless, when the experiments were scaled up to bubble column bioreactors, a higher biomass production coincided with more pigments per $\mathrm{g}$ of dry biomass at $\mathrm{pH} 3.5$, and the high aeration rates $(0.5$ and $1.3 \mathrm{vvm})$ were obtained (Figure 3$)$.

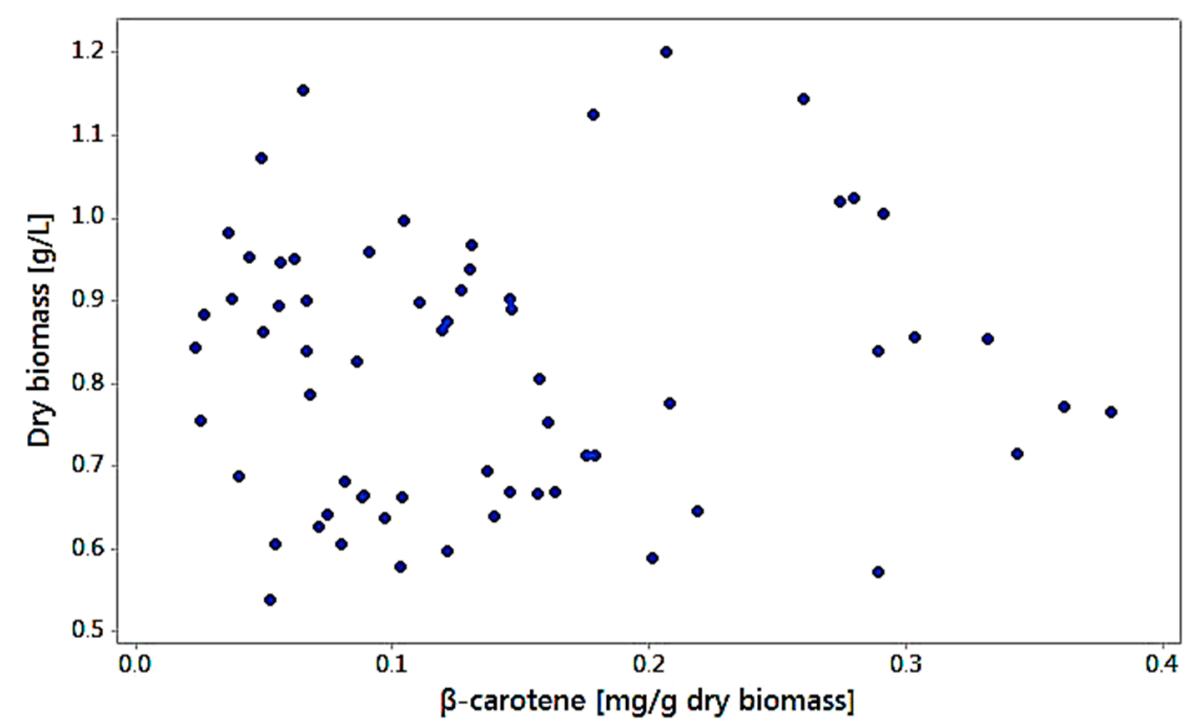

Figure 6. Relation between dry biomass and pigment production showed no clear correlation towards a negative correlation between high biomass production and pigmentation.

The results from the shake-flask experiments suggested that the combined effect of factors impacting observed pigment and biomass production can vary significantly with a change of nutrient level or growth conditions, which might explain the different results obtained from the shake-flasks and the bubble column bioreactor. Cellular growth was not inhibited as a result of low $\mathrm{pH}$, and a positive relationship between biomass concentration and pigment production in bench-scale bioreactors was 
observed. The final harvested biomass from the bubble column bioreactors was slightly higher for the cultivations grown at $\mathrm{pH} 3.5$ compared to those grown at $\mathrm{pH} 5.5$, irrespective of carbon source (Figure 4a). The high biomass production at $\mathrm{pH} 3.5$ can be explained by the higher carbon consumption abilities $(7.58 \pm 0.4 \mathrm{~g}$ total carbon source consumed/L and $5.39 \pm 0.5 \mathrm{~g}$ total carbon source/ $\mathrm{L}$ at the end of cultivation for $\mathrm{pH} 3.5$ and 5.5, respectively) at these conditions. Consequently, increased pigment production could be related to the higher carbon consumption as a faster depletion of the carbon source gives an earlier stress response to the cells. The maximal biomass concentration was also obtained with high aeration (Figure $4 b$ ), which coincided with high pigment production, demonstrating that the conditions for the production of biomass are suited for obtaining pigments. Production of biomass did not increase in relation to pigmentation, as the experiments with 0.5 and $1.3 \mathrm{vvm}$ resulted in similar amounts of biomass regardless of the differences in pigment production.

\section{Conclusions}

Pigment production by $N$. intermedia was found to be significantly influenced by the carbon source mannose and the addition of the cofactors $\mathrm{Mg}^{2+}$ and $\mathrm{Mn}^{2+}$ favored pigment accumulation. Pigment production remained unaffected by addition of only $\mathrm{Zn}^{2+}$, but $\mathrm{Zn}^{2+}$ seemed to play a role in combination with carbon, nitrogen and $\mathrm{Mg}^{2+}$. When scaling up the process in a bioreactor, the growth and pigment production differed depending on the cultivation conditions. High aeration and low $\mathrm{pH}$ seemed to favor both biomass and pigment production. The production of pigments seems to imply a stronger effect caused more by low $\mathrm{pH}$ and high aeration than the nitrogen and carbon source added, and it is likely that other cultural and environmental factors combine to activate mechanisms related to metabolic controls and defense mechanisms. The results point towards the potential of using $N$. intermedia as a novel source of pigment, which may be of interest to the food and feed industry.

Acknowledgments: The authors would like to thank the Lantmännen Research Foundation and the University of Borås for financial support.

Author Contributions: Rebecca Gmoser, Jorge A. Ferreira, Patrik R. Lennartsson and Mohammad J. Taherzadeh conceived the idea and the structure of the manuscript, Rebecca Gmoser wrote the majority of the paper and performed all the experiments with support from Jorge A. Ferreira and Magnus Lundin who helped with statistical integration. Jorge A. Ferreira, Patrik R. Lennartsson and Mohammad J. Taherzadeh revised the manuscript and contributed with valuable discussions. All authors read and approved the final manuscript.

Conflicts of Interest: The authors declare no conflict of interest.

\section{References}

1. Gusdinar, T.; Singgih, M.; Priatni, S.; Sukmawati, A.; Suciati, T. Enkapsulasi dan stabilitas pigmen karotenoid dari Neurospora intermedia n-1 (encapsulation and the stability of carotenoids from Neurospora intermedia n-1). J. Mns. Lingkung. 2014, 18, 206-211.

2. Holme, I. Sir william henry perkin: A review of his life, work and legacy. Coloration Technol. 2006, 122, 235-251. [CrossRef]

3. Yoo, A.Y.; Alnaeeli, M.; Park, J.K. Production control and characterization of antibacterial carotenoids from the yeast Rhodotorula mucilaginosa ay-01. Process Biochem. 2016, 51, 463-473. [CrossRef]

4. Torres, F.A.E.; Zaccarim, B.R.; de Lencastre Novaes, L.C.; Jozala, A.F.; Dos Santos, C.A.; Teixeira, M.F.S.; Santos-Ebinuma, V.C. Natural colorants from filamentous fungi. Appl. Microbiol. Biotechnol. 2016, 100, 2511-2521. [CrossRef] [PubMed]

5. Saini, R.K.; Nile, S.H.; Park, S.W. Carotenoids from fruits and vegetables: Chemistry, analysis, occurrence, bioavailability and biological activities. Food Res. Int. 2015, 76, 735-750. [CrossRef] [PubMed]

6. Hernández-Almanza, A.; Montanez, J.C.; Aguilar-González, M.A.; Martínez-Ávila, C.; Rodríguez-Herrera, R.; Aguilar, C.N. Rhodotorula glutinis as source of pigments and metabolites for food industry. Food Biosci. 2014, 5, 64-72. [CrossRef]

7. McNeil, B.; Archer, D.; Giavasis, I.; Harvey, L. Microbial Production of Food Ingredients, Enzymes and Nutraceuticals; Elsevier Science: Burlington, MA, USA, 2013. 
8. Singgih, M.; Andriatna, W.; Damayanti, S.; Priatni, S. Carotenogenesis study of neurospora intermedia n-1 in liquid substrate fermentation. J. Chem. Pharm. Res. 2015, 7, 842-847.

9. Da Costa Souza, P.N.; Grigoletto, T.L.B.; de Moraes, L.A.B.; Abreu, L.M.; Guimarães, L.H.S.; Santos, C.; Galvão, L.R.; Cardoso, P.G. Production and chemical characterization of pigments in filamentous fungi. Microbiology 2016, 162, 12-22. [CrossRef] [PubMed]

10. Nout, M.J.R.; Aidoo, K.E. Asian fungal fermented food. In Industrial applications; Springer: Berlin, Germany, 2011; pp. 29-58.

11. Perkins, D.D.; Davis, R.H. Evidence for safety of neurospora species for academic and commersial uses. Appl. Environ. Microbiol. 2000, 66, 5107-5109. [CrossRef] [PubMed]

12. Pandit, A.M. Ramesh Life-history of neurospora intermedia in a sugar cane field. J. Biosci. 1996, $21,57-79$. [CrossRef]

13. Ferreira, J.A.; Lennartsson, P.R.; Taherzadeh, M.J. Production of ethanol and biomass from thin stillage using food-grade zygomycetes and ascomycetes filamentous fungi. Energies 2014, 7, 3872-3885. [CrossRef]

14. Mapari, S.A.; Thrane, U.; Meyer, A.S. Fungal polyketide azaphilone pigments as future natural food colorants? Trends Biotechnol. 2010, 28, 300-307. [CrossRef] [PubMed]

15. Gmoser, R.; Ferreira, J.A.; Lennartsson, P.R.; Taherzadeh, M.J. Filamentous ascomycetes fungi as a source of natural pigments. Fungal Biol. Biotechnol. 2017, 4, 4. [CrossRef] [PubMed]

16. Sues, A.; Millati, R.; Edebo, L.; Taherzadeh, M.J. Ethanol production from hexoses, pentoses, and dilute-acid hydrolyzate by mucor indicus. FEMS Yeast Res. 2005, 5, 669-676. [CrossRef] [PubMed]

17. Lv, J.; Zhang, B.-B.; Liu, X.-D.; Zhang, C.; Chen, L.; Xu, G.-R.; Cheung, P.C.K. Enhanced production of natural yellow pigments from monascus purpureus by liquid culture: The relationship between fermentation conditions and mycelial morphology. J. Biosci. Bioeng. 2017, 124, 452-458. [CrossRef] [PubMed]

18. Varzakakou, M.; Roukas, T.; Kotzekidou, P.; Giamoustaris, A. Effect of non-ionic surfactants and beta-ionone on the morphology of blakeslea trispora and carotenoids production from cheese whey in submerged aerobic growth: A statistical approach. Food Biotechnol. 2010, 24, 197-214. [CrossRef]

19. Méndez, A.; Pérez, C.; Montañéz, J.C.; Martínez, G.; Aguilar, C.N. Red pigment production by penicillium purpurogenum gh2 is influenced by ph and temperature. J. Zhejiang Univ. Sci. B 2011, 12, 961-968. [CrossRef] [PubMed]

20. Sandmann, G. Photoregulation of carotenoid biosynthesis in mutants of Neurospora crassa: Activities of enzymes involved in the synthesis and conversion of phytoene. Zeitschrift für Naturforschung C 1993, 48, 570-574.

21. Yang, Y.; Liu, B.; Du, X.; Li, P.; Liang, B.; Cheng, X.; Du, L.; Huang, D.; Wang, L.; Wang, S. Complete genome sequence and transcriptomics analyses reveal pigment biosynthesis and regulatory mechanisms in an industrial strain, Monascus purpureus yy-1. Sci. Rep. 2015, 5, 8331. [CrossRef] [PubMed]

22. Ku, S.; Zheng, H.; Park, M.S.; Ji, G.E. Optimization of $\beta$-glucuronidase activity from Lactobacillus delbrueckii Rh2 and its use for biotransformation of baicalin and wogonoside. J. Korean Soc. Appl. Biol. Chem. 2011, 54, 275-280. [CrossRef]

23. $\mathrm{Ku}, \mathrm{S}$. Finding and producing probiotic glycosylases for the biocatalysis of ginsenosides: A mini review. Molecules 2016, 21, 645. [CrossRef] [PubMed]

24. Marcoleta, A.; Niklitschek, M.; Wozniak, A.; Lozano, C.; Alcaíno, J.; Baeza, M.; Cifuentes, V. Glucose and ethanol-dependent transcriptional regulation of the astaxanthin biosynthesis pathway in Xanthophyllomyces dendrorhous. BMC Microbiol. 2011, 11, 190. [CrossRef] [PubMed]

25. Rolland, F.; Winderickx, J.; Thevelein, J.M. Glucose-sensing and-signalling mechanisms in yeast. FEMS Yeast Res. 2002, 2, 183-201. [CrossRef] [PubMed]

26. Alcaíno, J.; Bravo, N.; Córdova, P.; Marcoleta, A.E.; Contreras, G.; Barahona, S.; Sepúlveda, D.; Fernández-Lobato, M.; Baeza, M.; Cifuentes, V. The involvement of mig1 from Xanthophyllomyces dendrorhous in catabolic repression: An active mechanism contributing to the regulation of carotenoid production. PLoS ONE 2016, 11, e0162838. [CrossRef] [PubMed]

27. Bhosale, P. Environmental and cultural stimulants in the production of carotenoids from microorganisms. Appl. Microbiol. Biotechnol. 2004, 63, 351-361. [CrossRef] [PubMed]

28. Paoletti, R.; Kritchevsky, D. Advances in Lipid Research; Elsevier: Amsterdam, The Netherlands, 2015; Volume 21. 
29. An, G.-H.; Chang, K.-W.; Johnson, E.-A. Effect of oxygen radicals and aeration on carotenogenesis and growth of phaffia rhodozyma (Xanthophyllomyces dendrorhous). J. Microbiol. Biotechnol. 1996, 6, 103-109.

30. Clastre, M.; Bantignies, B.; Feron, G.; Soler, E.; Ambid, C. Purification and characterization of geranyl diphosphate synthase from vitis vinifera 1. Cv muscat de frontignan cell cultures. Plant Physiol. 1993, 102, 205-211. [CrossRef] [PubMed]

31. The UniProt Consortium. Uniprot: The universal protein knowledgebase. Nucl. Acids Res. 2017, 45, D158-D169.

32. Mitzka-Schnabel, U. Carotenogenic enzymes from neurospora. Pure Appl. Chem. 1985, 57, $667-669$. [CrossRef]

33. Johnson, G.T.; McHan, F. Some effects of zinc on the utilization of carbon sources by Monascus purpureus. Mycologia 1975, 67, 806-816. [CrossRef] [PubMed]

34. Said, F.M.; Brooks, J.; Chisti, Y. Optimal c: N ratio for the production of red pigments by Monascus ruber. World J. Microbiol. Biotechnol. 2014, 30, 2471-2479. [CrossRef] [PubMed]

35. Carels, M.; Shepherd, D. The effect of different nitrogen sources on pigment production and sporulation of Monascus species in submerged, shaken culture. Can. J. Microbiol. 1977, 23, 1360-1372. [CrossRef] [PubMed]

36. Nuraini, S.; Latif, S.A. Improving the quality of tapioca by product through fermentation by Neurospora crassa to produce \$ carotene rich feed. Pak. J. Nutr. 2009, 8, 487-490.

37. Rodríguez-Ortiz, R.; Limón, M.C.; Avalos, J. Regulation of carotenogenesis and secondary metabolism by nitrogen in wild-type Fusarium fujikuroi and carotenoid-overproducing mutants. Appl. Environ. Microbiol. 2009, 75, 405-413. [CrossRef] [PubMed]

38. Griffin, D.H. Chemical requirements for growth. In Fungal Physiology, 2nd ed.; John Wiley \& Sons: Hoboken, NJ, USA, 1996; p. 133.

39. Sanchez, S.; Rutz, B.; Rodríguez-Sanoja, R. Microbial production of carotenoids. In Microbial Production of Food Ingredients, Enzymes and Nutraceuticals; McNeil, B., Archer, D., Giavasis, I., Harvey, L., Eds.; Elsevier Science: Burlington, MA, USA, 2013; pp. 194-223.

40. Velmurugan, P.; Lee, Y.H.; Nanthakumar, K.; Kamala-Kannan, S.; Dufossé, L.; Mapari, S.A.S.; Oh, B.T. Water-soluble red pigments from Isaria farinosa and structural characterization of the main colored component. J. Basic Microbiol. 2010, 50, 581-590. [CrossRef] [PubMed]

41. Luo, H.; Niu, Y.; Duan, C.; Su, H.; Yan, G. A ph control strategy for increased $\beta$-carotene production during batch fermentation by recombinant industrial wine yeast. Process Biochem. 2013, 48, 195-200. [CrossRef]

42. Shin, C.S.; Kim, H.J.; Kim, M.J.; Ju, J.Y. Morphological change and enhanced pigment production of Monascus when cocultured with Saccharomyces cerevisiae or Aspergillus oryzae. Biotechnol. Bioeng. 1998, 59, 576-581. [CrossRef]

43. Hajjaj, H.; Blanc, P.; Groussac, E.; Uribelarrea, J.-L.; Goma, G.; Loubiere, P. Kinetic analysis of red pigment and citrinin production by Monascus ruber as a function of organic acid accumulation. Enzyme Microb. Technol. 2000, 27, 619-625. [CrossRef]

44. Ahn, J.; Jung, J.; Hyung, W.; Haam, S.; Shin, C. Enhancement of monascus pigment production by the culture of Monascus sp. J101 at low temperature. Biotechnol. Progress 2006, 22, 338-340. [CrossRef] [PubMed]

(C) 2018 by the authors. Licensee MDPI, Basel, Switzerland. This article is an open access article distributed under the terms and conditions of the Creative Commons Attribution (CC BY) license (http://creativecommons.org/licenses/by/4.0/). 